\title{
Chain Interdependencies, Measurement Problems, and Efficient Governance Structure: Cooperatives versus Publicly Listed Firms
}

\author{
Li Feng and George Hendrikse
}

forthcoming in European Review of Agricultural Economics

\begin{tabular}{|l|l|}
\hline \multicolumn{2}{|l|}{ ERIM REPORT SERIES RESEARCH IN MANAGEMENT } \\
\hline ERIM Report Series reference number & ERS-2011-001-ORG \\
\hline Publication & January 2011 \\
\hline Number of pages & 15 \\
\hline Persistent paper URL & http://hdl.handle.net/1765/22720 \\
\hline Email address corresponding author & ghendriskse@rsm.nl \\
\hline Address & Erasmus Research Institute of Management (ERIM) \\
& RSM Erasmus University / Erasmus School of Economics \\
& Erasmus Universiteit Rotterdam \\
& P.O.Box 1738 \\
& 3000 DR Rotterdam, The Netherlands \\
& Phone: + 31 10 408 1182 \\
& Fax: $\quad+31104089640$ \\
& Email: info@erim.eur.nl \\
& Internet: $\quad$ www.erim.eur.n! \\
\hline
\end{tabular}

Bibliographic data and classifications of all the ERIM reports are also available on the ERIM website: www.erim.eur.nl 


\section{ERASMUS RESEARCH INSTITUTE OF MANAGEMENT}

\section{REPORT SERIES}

\section{RESEARCH IN MANAGEMENT}

\begin{tabular}{|c|c|}
\hline \multicolumn{2}{|c|}{ ABSTRACT AND KEYWORDS } \\
\hline Abstract & $\begin{array}{l}\text { We determine the circumstances when the absence of public listing, often believed to be a } \\
\text { disadvantage, makes a cooperative the unique efficient governance structure. This is } \\
\text { established in a multi-task principal-agent model, capturing that cooperatives are not publicly } \\
\text { listed and their CEOs have to bring the downstream enterprise to value as well as to serve } \\
\text { upstream member interests. Not having a public listing prevents the CEO from choosing the } \\
\text { level of the downstream activities too high. Cooperatives are uniquely efficient when the } \\
\text { upstream marginal product multiplied with a function increasing in the strength of the chain } \\
\text { complementarities is higher than the downstream marginal product. }\end{array}$ \\
\hline Free Keywords & chains, measurement, governance, cooperatives \\
\hline Availability & $\begin{array}{l}\text { The ERIM Report Series is distributed through the following platforms: } \\
\text { Academic Repository at Erasmus University (DEAR), DEAR ERIM Series Portal } \\
\text { Social Science Research Network (SSRN), SSRN ERIM Series Webpage } \\
\text { Research Papers in Economics (REPEC), REPEC ERIM Series Webpage }\end{array}$ \\
\hline Classifications & $\begin{array}{l}\text { The electronic versions of the papers in the ERIM report Series contain bibliographic metadata } \\
\text { by the following classification systems: } \\
\text { Library of Congress Classification, (LCC) LCC Webpage } \\
\text { Journal of Economic Literature, (JEL), JEL Webpage } \\
\text { ACM Computing Classification System CCS Webpage } \\
\text { Inspec Classification scheme (ICS), ICS Webpage }\end{array}$ \\
\hline
\end{tabular}




\title{
Chain Interdependencies, Measurement Problems, and Efficient
}

\section{Governance Structure: Cooperatives versus Publicly Listed Firms}

\author{
Li Feng \\ George Hendrikse ${ }^{1}$ \\ (forthcoming in European Review of Agricultural Economics)
}

\begin{abstract}
We determine the circumstances when the absence of public listing, often believed to be a disadvantage, makes a cooperative the unique efficient governance structure. This is established in a multi-task principal-agent model, capturing that cooperatives are not publicly listed and their CEOs have to bring the downstream enterprise to value as well as to serve upstream member interests. Not having a public listing prevents the CEO from choosing the level of the downstream activities too high. Cooperatives are uniquely efficient when the upstream marginal product multiplied with a function increasing in the strength of the chain complementarities is higher than the downstream marginal product.
\end{abstract}

Keywords: Chains, Measurement, Governance, Cooperatives.

1 Li Feng, Department of Economics, Swedish University of Agricultural Sciences, Uppsala, Sweden, fengli8386@gmail.com and George Hendrikse, Rotterdam School of Management, Erasmus University, Totterdam, Netherlands, ghendrikse@ rsm.nl. We are grateful for the insightful comments of an anonymous referee. 
'These figures suggest that cooperatives tend to operate in the low value-added, firststage food manufacturing industries.'

Cook, 1995, p1154

\section{Introduction}

Some researchers doubt the efficiency of cooperatives and argue that cooperatives suffer from a host of problems unique to this specific form of governance. Stewart (1993) even asserts that a business cannot be successfully run if its customers or suppliers are deeply involved in running it because there is too much conflict of interest. Yet, cooperatives and investor owned firms (IOFs) coexist in many sectors of most modern economies and compete for market share, especially in the agricultural sector where cooperatives have played an active role for a very long time in many countries (Hansmann, 1996).

A cooperative is an enterprise collectively owned by many independent farmers as input suppliers in a production chain. The members own collectively a joint resource where they either further process or market their produce. They delegate certain rights to the cooperative enterprise. Subsequently, the cooperative enterprise concludes contracts with members, specifying for example delivery requirements. The vertical ties between the members and the processor therefore consist of a transaction element and an ownership element. In contrast, an IOF processor is a firm owned by outside investors and it has merely a transactional relationship with its input suppliers.

An important agent in bringing an enterprise to value is the CEO (Chief Executive Officer). This is reflected in the massive amount of research focusing on what guides CEO behavior (see for example Babchuk and Fried, 2003). An important part of the research attention is executive compensation because it can help in rectifying the agency problem between the CEO and the owner(s). The relationship between the principal and the agent differs between a cooperative and an IOF. The situation in cooperatives is most likely more complex than a standard principal-agent relationship in an IOF. First, the tasks of a cooperative CEO consist of more dimensions due to the 'cooperative's goal of jointly maximizing member and cooperative returns' (Peterson and Anderson, 1996, p376). Members are users in addition to owners of the firm. They have at least two sets of concerns: owner concerns and user concerns. Owner concerns revolve around the security and overall profitability of their investments in the cooperative. User concerns include issues of the pricing and quality of product and services, which influence the profitability of their individual farm enterprise (Staatz, 1987). These two concerns are reflected in the members' expectation regarding the management.

Second, the incentive contract of a CEO is based on a performance measurement system, creating incentives that align the goal of the agent with that of the organization. However, there are no simple indicators of cooperative managerial performance or automatic incentive systems (such as stock options) to close the gap in interests. Giving a CEO equity in the business, a common way to tie the CEO's wealth to firm performance and thus to alleviate the interests conflict in IOFs, is uncommon in cooperatives. There are several reasons. One reason is that an (outside) cooperative CEO is not eligible to hold 
equity in the business. Another reason is that a CEO would receive only limited benefits from such ownership given the fact that most cooperatives respond to the absence of a public listing by adopting a conservative valuation method regarding the collective capital, resulting in the cooperative stock hardly appreciating in value (Trechter et al., 1997). Given these additional complexities in cooperatives, designing a contract ensuring the mutual compatibility of a cooperative's goals and the CEO's incentives has to be even more difficult.

These observations inspire the following questions: What is the impact of the absence of public listing and the dual role of members in a cooperative on the behavior of the CEO? When is a cooperative (with its member ownership and its lack of public listing) uniquely efficient? These questions will be addressed by incorporating the above distinctions between cooperatives and IOFs in a multi-task principal-agent model. We specify an upstream and a downstream activity, their interdependency, and a performance measure for the CEO capturing the difference in public listing between the two governance structures. This allows us to determine the circumstances when a cooperative is the unique efficient governance structure. ${ }^{2}$

We position our article in four ways. First, most studies regarding contract choice in agrarian economics using the principal-agent model are geared to the relationship between a landowner and a farmer (Hayami and Otsuka, 1993). We address the relationship between farmers and the CEO of a cooperative. Second, Fulton and Hueth (2009) indicate that cooperative conversions, failures, and restructurings are often due to poor management, next to lack of capital, property rights problems and portfolio problems. They observe regarding cases 'that were identified as having poor management were also identified as having significant agency problems'. This article addresses on the one hand these agency problems by analyzing the impact of the performance measurement scheme on managerial performance, and on the other hand identifies the sectors in which cooperatives are most likely to be successful. A third way to position the article is that a variety of corporate forms has to be considered when studying the nature of the firm (Hansmann, 1996). A cooperative is from this perspective an informative counterfactual for the much studied publicly-listed corporation. To be more specific, a cooperative has various special features which distinguish it from other governance structures. One of the objectives of research regarding cooperatives is to show that these features may actually be desirable, despite the widespread belief that they are not. In this article we demonstrate that the absence of a public listing, often believed as a disadvantage of cooperatives, can make a cooperative uniquely efficient. Finally, issues regarding the governance of enterprises are often distinguished into income and decision rights (Hansmann, 1996). Income rights address the question 'How are benefits and costs allocated?', i.e. they specify the rights to receive the benefits, and obligations to pay the costs, that are associated with the use of an asset. Decision rights in the form of authority and responsibility address the question 'Who has authority or control?', i.e. they concern all rights and rules regarding the deployment and use of assets. This article is about income rights, whereas Hendrikse and Veerman (2001a, 2001b) are about decision

\footnotetext{
${ }^{2}$ This article is not the first to identify these circumstances. We like to mention Bontems and Fulton (2009), Hendrikse (1998), Hendrikse and Veerman (2001a, 2001b), and Sexton (1986).
} 
rights. It entails implicitly that the ownership role is subordinate to the user / patron role in this article.

The next section presents the model. Section 3 identifies the efficient governance structure. The strategic choice of performance measure is addressed in section 4 . Conclusions and research directions are formulated in the final section.

\section{Model}

A multi-task principal-agent model (Gibbons, 1998) is developed to capture governance structure differences between cooperatives and IOFs. The model consists of a two-stage non-cooperative game. In the first stage, the principal (i.e. the owner) chooses the strength of incentives while the agent (i.e., the CEO)'s optimal choice of activities is determined in the second stage of the game. Assume that a CEO can take two actions, $a_{D}$ and $a_{U}$. First, denote $a_{D}$ as the CEO's action to advance the value of the downstream firm. Examples are setting long-term goals, establishing policies and standards, determining long-term financing needs and sources, and setting strategies (Blanchard et al, 1996). According to Merchant (1990), CEOs allocates their time over eight categories of activities: 1) new product development, 2) improvement of existing products/services, 3) adjusting/improving production processes, 4) employee development, 5) capacity expansion, 6) improvement of information systems, 7) execution of current production processes, and 8) advertising and sales promotion.

Second, denote $a_{U}$ as the action adding value to the upstream suppliers. In addition to the activities mentioned above, a cooperative CEO needs to take actions that create value for the upstream members because of the user-owner feature of cooperatives. Three extra categories are specified. The first category is improvement of member involvement and member loyalty. Compared with his IOF counterpart, the cooperative CEO is more interdependent and interactive when coping with the user-owners. As a leader of a community-based organization, he needs to be particularly effective in fostering group cohesiveness, a key component in improving member loyalty. The second category is vertical information exchange. A cooperative CEO once informed us that he spent at least half of his time communicating with member patrons. Members have different preferences as to price, cost allocation, and equity retirement polices, which affect both the cooperative and the member enterprises. They have more formal and informal channels to communicate their desires to the CEO than do patrons of an IOF and thus are able to exercise cheaper "voice" (Staatz, 1987). Meanwhile, a cooperative CEO must actively acquire useful information in discovering the optimal choice (Cook, 1994). The third category is member coordination and improvement of member relations. A cooperative CEO takes a more integrated view of the members' fixed costs when attempting to optimize the vaguely defined objective function of the firm. The more heterogeneous the membership, the more will be the difficulty for the CEO to form consensus and viable internal coalitions. The CEOs, particularly those of large, diversified cooperatives, need to spend considerable time and effort in negotiating and meeting the expectation of members. They are required to reduce the increasingly 
heterogeneous interests to more homogeneous interests to capture the benefits of coordination (Cook, 1994).

The CEO's total contribution to firm value is denoted by $y$. Denote the marginal product of action $a_{U}$ and $a_{D}$ by $f_{U}$ and $f_{D}$. The production function is $y=f_{U} a_{U}+f_{D} a_{D}+\varepsilon$, where $\varepsilon$ is a stochastic variable with expected value of zero, representing the noise in the production process that is beyond the agent's control. Given the difficulty in measuring the exact overall effect of the CEO's actions on firm value, no compensation contract based on $y$ can be enforced in court. Therefore, an alternative performance measure $p$ becomes necessary. Suppose the technology of performance measurement takes the form $p=\mathrm{g}_{U} \mathrm{a}_{U}+\mathrm{g}_{D} \mathrm{a}_{D}+\phi$, where $g_{U}, g_{D}$ denote the performance measurement parameter, i.e., the weight attached to $a_{U}, a_{D}$, and $\phi$ denotes the noise in performance measurement with expected value of zero. Suppose the compensation contract specifies the wage $w$ paid to the CEO as a linear function of $p$, i.e. $w=s+b p$, where $s$ stands for the salary and $b$ for the bonus rate. The principal's payoff is the difference between the CEO's total contribution to firm value and the wage paid: $\pi=y-w$. The CEO's payoff is the difference between the wage received and the cost of the actions taken: $U=w-c\left(a_{U}, a_{D}\right)$. Assume that the cost function is $c\left(a_{U}, a_{D}\right)=\frac{a_{U}{ }^{2}}{2}+k a_{U} a_{D}+\frac{a_{D}^{2}}{2}$, where $-1<\mathrm{k}<1$ (Dixit, 2002). The parameter $k$ captures interdependencies between the upstream and downstream activities in the production chain. There are no interdependencies when $\mathrm{k}=0$. When $0<\mathrm{k}<1$, the two tasks are substitutes, i.e., more effort in $a_{U}$ increases the marginal cost of effort in $a_{D}$, therefore enhancing the marginal incentive payment for greater output of $a_{U}$ draws effort away from $a_{D}$. Examples of substitutable tasks are the time spent by a CEO in communicating with the input suppliers and the time spent on the business strategies of the firm. When the workload of the CEO is fixed, the more he works with the suppliers, the less time is left to spend on the strategies. When $-1<\mathrm{k}<0$, the two tasks are complements, implying that the interaction between the two tasks strengthens incentives for both. ${ }^{3}$ An example of complementary tasks is the CEO's coordination role between the suppliers and the enterprise. Well known is the matching problem regarding sugar beets between the delivery of each farmer's harvest and the capacity of the processing plant. A farmer likes to deliver his harvest immediately to the processor, while the processor likes to spread the deliveries in order to reduce the idleness of the plant. More knowledge of one side facilitates coordination with the other side.

Differences between a cooperative and an IOF are reflected in their restrictions on the parameters in the production function and performance measure. First, a CEO's contribution to firm value depends on the organizational form. In cooperatives, it is equivalent to the change in total member value. Members want to bring both upstream farms and the downstream cooperative to value, i.e., $f_{U}>0, f_{D}>0$. Investors of an IOF

2 The cost function is superadditive when $\mathrm{k}<0$. 
processor care only about the value of the firm and consequently the CEO's action that increases firm value, i.e., $f_{U}=0, f_{D}>0$. Second, the performance measures of IOFs and cooperatives differ. It is not unusual in IOFs that the CEO's bonus is paid in the form of firm shares, i.e., $g_{D}>0$. The CEO of an IOF processor will of course not be rewarded based on a performance measure taking upstream activities into account, i.e. $g_{U}=0$. Cooperatives lack a public listing. They are therefore not able to pay the CEO with shares reflecting the value of the downstream enterprise. We capture this observation by assuming $g_{D}=0$ in a cooperative. ${ }^{4}$ However, member interests are usually present in the incentive scheme for a cooperative CEO, e.g. by benchmarking the transfer price and production volume. This is reflected in our assumption that $g_{U}>0$ in cooperatives. Notice that these assumptions regarding the parameters in the performance measure scheme of the cooperative reflects that members are prioritized rather than the downstream activities, which is of course popular with members, especially those who are close to retirement.

To summarize, cooperative members' plurality of interests is represented by $f_{U}>0$, while the absence of patron-members, and therefore serving their interests, in an IOF is represented by $g_{U}=0$. The absence of public listing of a cooperative is embodied by $g_{D}=0$, while the use of the stock price in an IOF's performance measure is captured by $g_{D}>0$. The distinct features of both governance structures are presented in table 1. Our specifications imply implicitly, except for these zeros, that the parameters in the production function and the performance measure remain the same across different governance structures.

Insert table 1 about here

\section{Efficient governance structure}

We use backward induction to solve the game. We start therefore in the second stage of the game in order to determine the equilibrium level of tasks chosen by the CEO. Subsequently we determine in stage one the equilibrium bonus rate. The CEO's optimal action is determined by maximizing his expected utility, i.e., $\max _{a_{U}, a_{D}} E(U)$, where

$$
E(U)=E\left[w-c\left(a_{U}, a_{D}\right)\right]=s+b\left(\mathrm{~g}_{U} \mathrm{a}_{U}+\mathrm{g}_{D} \mathrm{a}_{D}\right)-\left(\frac{a_{U}^{2}}{2}+k a_{U} a_{D}+\frac{a_{D}^{2}}{2}\right) .
$$

Setting the first derivative of the expected utility function with respect to $a_{U}, a_{D}$ equal to

3 We are not stating that a cooperative has no information at all about the downstream activities, but our model will focus on the impact of lacking certain information. 
zero results in the first order conditions $b g_{U}=\frac{\partial c}{\partial a_{U}}$ and $b g_{D}=\frac{\partial c}{\partial a_{D}}$. This characterizes the CEO's optimal actions $a_{U}^{*}(b)$ and $a_{D}^{*}(b)$.

The payoff-maximizing reply in the second stage of the game is anticipated in the first stage when the principal chooses $b^{*} . b^{*}$ is determined by maximizing the expected total surplus, that is, $\max _{b} E(\pi+U)$, where $E(\pi+U)=E\left[y-c\left(a_{U}, a_{D}\right)\right]=f_{U} a_{U}^{*}+f_{D} a_{D}^{*}-c\left(a_{U}^{*}, a_{D}^{*}\right)$.

The specification of the two governance structures in table 1 is used to determine the equilibrium results. The efficient bonus rate for a cooperative is $b^{*}=\frac{\left(f_{U}-k f_{D}\right)}{g_{U}}$. The cooperative CEO's equilibrium actions are $a_{D}^{*}=\frac{-k\left(f_{U}-k f_{D}\right)}{1-k^{2}}$ and $a_{U}^{*}=\frac{f_{U}-k f_{D}}{1-k^{2}}$. The total surplus is $\frac{\left(f_{U}-k f_{D}\right)^{2}}{2\left(1-k^{2}\right)}$. Similarly, the efficient bonus rate for an IOF is $b^{*}=f_{D} / g_{D}$ and the optimal actions of a downstream IOF CEO are, $a_{D}^{*}=\frac{f_{D}}{1-k^{2}}$ and $a_{U}^{*}=\frac{-k f_{D}}{1-k^{2}}$. The surplus generated is $\frac{f_{D}{ }^{2}}{2\left(1-k^{2}\right)}$.

A cooperative has to be compared with another governance structure in order to determine when it is efficient. One possibility is to focus on the misalignment between the performance measure and the production function (coefficients) by comparing a cooperative with an IOF (with a different value of the performance measurement parameter regarding the upstream activities). This is done by Gibbons (1998), but the importance of chain interdependencies is not reflected in such a comparison. Another possibility is to highlight that a cooperative consists of the upstream farmers and the downstream processor. Value is added at both stages of production by the cooperative. We capture this by comparing the surplus created by a cooperative with the joint surplus created by two independent IOFs, one upstream farmer and one downstream processor. We introduce therefore an upstream IOF farmer, with $f_{D}=0, f_{U}>0, g_{D}=0, g_{U}>0$. The equilibrium results for the upstream IOF are $b^{*}=f_{U} / g_{U}, a_{D}^{*}=\frac{-k f_{U}}{1-k^{2}}$, and $a_{U}^{*}=\frac{f_{U}}{1-k^{2}}$. The surplus generated is $\frac{f_{U}{ }^{2}}{2\left(1-k^{2}\right)}$.

\subsection{No interdependency, i.e. $k=0$}

If $\mathrm{k}=0$, the equilibrium results of the cooperative and the upstream IOF are identical, i.e., $b^{*}=f_{U} / g_{U}, a_{D}^{*}=0, a_{U}^{*}=f_{U}$. The equilibrium results of the downstream IOF are 
$b^{*}=f_{D} / g_{D}, a_{D}^{*}=f_{D}, a_{U}^{*}=0$. In equilibrium, the CEO of the downstream IOF has incentives to undertake only $a_{D}$, because the investors care only about $a_{D}$ and make the CEO's pay dependent only on $a_{D}$. Members of cooperatives, however, appreciate the CEO's actions on both dimensions but only compensate for $a_{U}$. Thus, only an incentive to increase $a_{U}$ is created and no incentive for $a_{D}$ exists even though it would increase firm value. The appearance of $a_{D}$ in the production function does not have any impact on the efficient bonus rate and subsequently on the CEO's equilibrium actions because it is not acknowledged in the performance measure. Consequently, the behavior of the cooperative CEO is exactly the same as the behavior of the CEO of the upstream IOF. When an action increases the member value without simultaneously increasing the performance measure, the CEO has no incentives to undertake it.

Straightforward calculations show that the total surplus of the cooperative, the upstream and downstream IOF are $\frac{1}{2} f_{U}^{2}, \frac{1}{2} f_{U}^{2}$ and $\frac{1}{2} f_{D}^{2}$ respectively. The total surplus created by a cooperative is identical to the surplus generated by an upstream IOF and is always less than the surplus created by the two IOFs, i.e. the cooperative is inefficient. Value would be created in the cooperative by developing downstream activities because $f_{D}>0$, but the cooperative CEO will not choose these activities because the performance measure does not put any weight on them. The difference in value creation between the two governance structures is therefore equal to the value created at the downstream IOF. This result is summarized in proposition 1.

Proposition 1: A cooperative is inefficient when $k=0$.

Another way to explain this result is that the cooperative is supposed to serve member interests and to generate maximum value in processing. However, the organizational structures required for the upstream and downstream tasks differ. The cooperative is designed for the former task, and therefore does not always perform the latter task well. The governance structure IOF consists of two separate entities, i.e. a downstream and an upstream IOF. It is tailored to each task separately. Section 3.2 will show that this result hinges on the assumption that the upstream and downstream activities are independent.

\subsection{Tasks are complements / substitutes, i.e. $-1<\mathrm{k}<0$ / $0<\mathrm{k}<1$}

As shown in the beginning of the section, $a_{U}$ for the downstream IOF and $a_{D}$ for the upstream IOF and the cooperative are not zero anymore in equilibrium if the tasks are substitutes or complements. Their actual levels will depend on the nature and the strength of the interaction effects.

The CEO of the downstream IOF will optimally choose to take more actions advancing the downstream value as compared with the case where $\mathrm{k}=0$, regardless the nature of the interaction between tasks. If $a_{U}$ can make $a_{D}$ less costly, he will take some actions $a_{U}$ in 
order to decrease the marginal cost of $a_{D}$, which will in turn increase $a_{D}^{*}$. A stronger complementarity effect results in a larger $a_{D}^{*}=\frac{f_{D}}{1-k^{2}}$ and $a_{U}^{*}=\frac{-k f_{D}}{1-k^{2}}$, i.e., more actions will be taken at both the upstream and downstream stage. If $a_{U}$ makes $a_{D}$ more costly, then a negative action on $a_{U}$ will be taken since it will decrease the marginal cost of action $a_{D}$, and therefore $a_{D}^{*}$ increases. Similarly, the CEO of the upstream IOF will optimally choose to take more actions advancing the upstream value when his tasks are interdependent.

When two actions are complements, a cooperative CEO will optimally choose a positive level of $a_{D}$, which in turn increases the equilibrium level of $a_{U}$ as compared with the case when $\mathrm{k}=0$. A stronger complementarity effect results in higher levels of $a_{D}^{*}$ and $a_{U}^{*}$. A high bonus rate will result in a high level of $a_{U}^{*}$, which will result in a higher $a_{D}^{*}$ due to the complementarity effect. Therefore, a principal valuing both actions has incentives to increase the bonus rate in order to increase both actions. The stronger is the complementarity effect, the larger is the efficient bonus rate. When the two tasks are substitutes, a high bonus rate drives the cooperative CEO to exert as much effort as possible to $a_{U}$ while taking no action or even negative action on $a_{D}$. Therefore, the principal will cut down the bonus rate. The efficient bonus rate will be smaller when the substitution effect is stronger.

We have shown earlier that the total surplus of a cooperative and two IOFs are $\frac{\left(f_{U}-k f_{D}\right)^{2}}{2\left(1-k^{2}\right)}, \frac{f_{D}{ }^{2}}{2\left(1-k^{2}\right)}$ and $\frac{f_{U}{ }^{2}}{2\left(1-k^{2}\right)}$ respectively if tasks are substitutes or complements. The comparison of the total surplus of the cooperative with the total surplus of the two IOFs is straightforward. It results in proposition 2.

Proposition 2: A cooperative is uniquely efficient if and only if $f_{D}<\frac{-2 k}{1-k^{2}} f_{U}$.

Interactions between the downstream and upstream activities may make the cooperative the unique efficient governance structure. These interactions in the cost function elicit new activities by the CEOs, i.e., the cooperative CEO will choose a positive level of the downstream activities, downstream activities are chosen also by the CEO at the upstream IOF, and upstream activities are put forward by the CEO at the downstream IOF. It turns out that the equilibrium level of upstream activities generated by the cooperative is identical to the level of upstream activities by the two IOFs together, while the level of downstream activities generated by the cooperative is lower than the level of downstream activities by the two IOFs together. Total output in a cooperative is therefore lower than in the IOFs. However, the decrease in total costs in a cooperative is even larger when the complementarities are sufficiently strong. The reason is that the decrease in the downstream activities by the cooperative CEO is limited due to $f_{U}>0$. This makes the cooperative the unique efficient governance structure, despite that the downstream 
activities are not recognized in the CEO's compensation scheme. The cooperative internalizes externalities to a certain extent by putting positive weight on serving member interests and generating maximum value in processing. Not having a public listing provides the cooperative with a commitment not to choose the level of the downstream activities too high. Proposition 2 also indicates that the cooperative is never efficient when the downstream and upstream activities are substitutes or independent.

Proposition 2 may also be interpreted in terms of a tradeoff between a measurement problem and a chain interdependency. In each IOF (upstream or downstream), there is no measurement problem and thus no agency cost since we have only one action which is valued in terms of revenues. This raises the question of the optimality of vertical separation versus vertical integration. Define the total surplus of the two separate IOFs as $W^{s}=\frac{f_{U}^{2}+f_{D}^{2}}{2\left(1-k^{2}\right)}$, where the subscript $\mathrm{S}$ means 'Separation'. Consider an integrated firm with no measurement problem, i.e. the f- and g-vector are completely aligned. Define the total surplus of this integrated firm as $\hat{W}=\hat{y}-c\left(\hat{a}_{U}, \hat{a}_{D}\right)$ with $\hat{a}_{i}=\frac{f_{i}-k f_{i}}{1-k^{2}}$ for $\mathrm{i}=\mathrm{U}, \mathrm{D}$ and $\hat{y}=\sum_{i=U, D} f_{i} \hat{a}_{i}$. It follows that $\hat{W}=W^{s}-\frac{k f_{U} f_{D}}{1-k^{2}}$. It is immediate that separation can only be optimal when actions are cost substitutes and never when actions are cost complements.

Now, if the integrated firm is a cooperative so that a measurement problem appears by definition, we already know that a cooperative yields a lower surplus than the corresponding efficient firm, i.e. $W^{\text {coop }}=\frac{\left(f_{U}-k f_{D}\right)^{2}}{2\left(1-k^{2}\right)}<\hat{W}$. The feature that $\lim _{k \rightarrow-1} W^{\text {coop }}=\hat{W}$ entails that the agency cost due to the measurement problem in the cooperative becomes negligible when $\mathrm{k}$ is approaching -1 . But as shown by proposition 2 , a cooperative is more efficient than two separated IOFs if and only if $\mathrm{k}$ is sufficiently negative, i.e. if and only if the agency cost of the cooperative is sufficiently small. Hence, when $\mathrm{k}$ is negative, there is a tradeoff between having potentially optimal integration but at an agency cost and having no agency cost but suboptimal separation between producing units.

Proposition 2 provides at least two indications where cooperatives are to be expected. First, cooperatives are expected in sectors where the marginal productivity at the downstream stage is below a certain level, which depends on the strength of the complementarities and the marginal productivity at the upstream stage of production. This is in line with the opening citation of this article. Second, the incidence of cooperatives varies between countries and over time. Hansmann (1999, p387) observes 'More generally and more strikingly, the overall share of economic activity accounted for by cooperatives is larger in advanced economies than it is in less-developed economies. And, more striking still, the market share of cooperatives in economic activity has grown throughout the $20^{\text {th }}$ century.' One development in the advanced economies is the rise of ICT, and its applications in the management of supply chains. Improving the coordination 
in supply chains entails an increase in the importance of chain complementarities, i.e. a decrease in the level of the chain interdependencies parameter $\mathrm{k}$ in our model. The inequality in proposition 2 indicates that cooperatives are the efficient organizational form in more sectors of the economy when the strength of chain complementarities increases.

\section{Strategic choice of performance measure}

This section argues that there may be a strategic rationale involved in the choice of the performance measure parameters. Strategic as well as efficiency considerations may determine the weights in the performance measure to establish alignment with the production function parameters. An early contribution is Vickers (1985). Notice that to study strategic performance measurement choice, there need to be (potential) competition between enterprises, i.e., there have to be at least two enterprises.

According to Fudenberg and Tirole (1984), three variables have to be specified in order to determine the payoff maximizing choice of performance measure in a strategic setting: the nature of the investment, the nature of the competitive process, and the entry condition. First, define the investment as the extent of member focus in the performance measure. If the extent of member focus is large, i.e., $g_{2}$ is much higher than $g_{1}$, then the profits of the rival firm will increase. The reason is that the CEO will dedicate a larger part of his time to activities related to the interests of members when the extent of member focus changes from small (S) to large (L), which goes at the expense of activities geared towards developing the cooperative enterprise. It entails that the investment is soft, because it establishes a positive relationship between investment in the weight of member focus in the performance measure and profits of the rival firm. Second, assume that the nature of the competitive process is characterized by strategic substitutes, i.e. reaction functions are downward sloping (figure 1). Third, two cases regarding the possibilities of market entry have to be distinguished (Fudenberg and Tirole, 1984): entry is inevitable or it is not. If entry is not inevitable, then a monopoly market structure arises endogenously by the choices of the two enterprises. Otherwise it is always a duopoly.

Insert figure 1 about here

The profit maximizing investment profile of the cooperative is to be aggressive in order to elicit a passive response by the rival, i.e. underinvestment in the weight put on member focus in the performance measure. Notice that in a setting with strategic substitutes no distinction has to be made regarding the entry condition. The payoff maximizing investment choice is the same in both cases regarding the entry condition because the market is characterized by a soft investment and strategic substitutes. This result is summarized in proposition 3.

Proposition 3: A cooperative puts a low weight on member focus in its performance measure in order to elicit passive behavior from a rival enterprise. 


\section{Conclusions and further research}

This article has developed a multi-task principal-agent model in order to address the effects of interdependencies between upstream and downstream activities and strategic performance measure choice. It is established that the interdependency between upstream and downstream activities is a possible source to make the cooperative the unique efficient governance structure. A necessary requirement for the efficiency of the cooperative is that this interdependency is a chain complementarity, and that it has to be above a certain level. This level is increasing in the ratio of the downstream and upstream marginal product, i.e. the chain complementarities have to be stronger when the downstream marginal product increases relative to the upstream marginal product. It entails that cooperatives are efficient only in sectors where the downstream marginal product is below a certain level, given the level of the upstream marginal product and the strength of the chain complementarities.

It is encouraging that the results are established in a highly stylized model. It provides a start for developing additional arguments for the widespread occurrence of cooperatives. One obvious possibility for further research is to relax the assumption that cooperatives have no information available regarding downstream activities to incorporate in the performance measure scheme of the CEO, e.g. accounting data or subjective performance measures. Relaxing this assumption may identify additional circumstances when the cooperative is an efficient governance structure.

Second, Trechter et al. (1997) is right that the CEO is important for the success of a cooperative. However, enterprises have a variety of means to address coordination and motivation problems, of which CEO compensation is one. Other instruments have therefore to be considered in combination with CEO compensation. For example, further research may incorporate additional internal control mechanism in cooperatives. The board of directors is usually elected by and from the membership, and is commonly representing member interests. It has more access to information inside the organization and have more at stake in the cooperative than their counterparts in IOFs have, and are thus expected to be a more active monitor and participant.

Third, the principal-agent model embodies various assumptions which are questioned by practitioners. For example, the model posits that the principal is in a very powerful position because he determines the details of the contract, while the agent decides subsequently regarding acceptance of the contract and the level of activities. It seems that the model allocates too much power to the principal, i.e. the members. In reality the CEO has often substantial power due to his superior information regarding final product markets and the details of similar compensation packages for his position (Hendrikse, 2007). He is therefore in a position to propose his own compensation package, while the board representing the members only can decide to accept or reject the compensation proposal. So, there seems to be a skewed power relationship between the board and the CEO in favor of the CEO. A related observation is that many researchers today think that there are problems associated with the vaguely defined property rights in cooperatives. 
Future research has to determine how our results are influenced by the degree of CEO power.

Fourth, our results can be related to growth and innovation of cooperatives versus IOFs. The nonmarketability of cooperative equity implies different attitudes towards growth between cooperatives and IOFs. Growth is the single most important determinant of stock price (Holmström, 1999). The growth of an IOF results in appreciation of equity, which can be realized by investors through selling their shares in the secondary market. An IOF CEO has thus incentives to accelerate the firm growth when his own pay and tenure are strongly tied to the stock price (Lerman and Parliament, 1991). The nonmarketability of cooperative equity, on the other hand, provides no incentives for the cooperative CEO to pursue firm growth. This is in line with our results predicting that the cooperative CEO spends less effort to advance downstream value, leading to slower growth in cooperative enterprises than in IOFs.

There are also differences to be expected regarding upstream versus downstream innovation. Upstream innovation mainly concerns the process innovation related to the existing products while the downstream innovation concerns development of new products. Cooperatives, according to many, are at a disadvantage in the innovation race with IOFs. For instance, Thirkell (1989) claims that cooperatives are generally not innovative or progressive. Given the discussion in previous sections, the emphasis of a cooperative on upstream member benefits entails that the process innovation in members' close interests is not necessarily ineffective or inactive as compared with that in an IOF. A cooperative normally only processes (or markets) the products from its members, and this makes product-orientation a characteristic of the cooperative business form. Furthermore, the fact that members have expertise and will bring new ideas about their products will strengthen the cooperative's search for product related differentiation. Based on our results we expect that the cooperatives focus more on upstream innovation with regard to the existing products than on the development of new products downstream. Empirical research has to shed light on these claims.

\section{References}

Bebchuk, L.A., and Fried, J.M. (2003). Executive Compensation as an Agency Problem, Journal of Economic Perspectives, 17(3): 71-92.

Blanchard, K., Schewe, C., Nelson, R., and A. Hiam, Exploring the World of Business, New York, Worth Publishers, 1996.

Bontems, P. and Fulton, M.E. (2009). Organizational Structure, Redistribution and the Endogeneity of Costs: Cooperatives, Investor-Owned Firms and the costs of Procurement, Journal of Economic Behavior \& Organization 72: 322-343.

Cook, M.L. (1995). The Future of U.S. Agricultural Cooperatives: A Neo-Institutional Approach, American Journal of Agricultural Economics 77: 1153-1159.

Cook, M.L. (1994). The Role of Management Behavior in Agricultural Cooperatives, Journal of Agricultural Cooperatives 9: 42-58.

Dixit, A. (2002). Incentives and Organizations in the Public Sector: An Interpretative Review, Journal of Human Resources 37(4): 696-727. 
Fudenberg, D. and Tirole, J. (1984). The Fat-Cat Effect, the Puppy-Dog Ploy, and the Lean and Hungry Look, American Economic Review 74(2): 361-366.

Fulton, M.E. and Hueth, B. (2009). Cooperative Conversions, Failures and Restructurings: An Overview, Journal of Cooperatives 23: i-xi.

Gibbons, R. (1998). Incentives in Organizations, Journal of Economic Perspectives 12: 115-132.

Hansmann, H. (1996). The Ownership of Enterprise. The Belknap Press of Harvard University Press, Cambridge, MA/London.

Hansmann, H. (1999). Cooperative Firms in Theory and Practice, The Finnish Journal of Business Economics 4: 387-403.

Hayami, Y. and Otsuka, K. (1993). The Economics of Contract Choice, Clarendon Press, Oxford.

Hendrikse G.W.J. (1998). Screening, Competition and the Choice of Marketing Cooperative as an Organizational Form, Journal of Agricultural Economics 49(2): 202-217.

Hendrikse, G.W.J., Two Vignettes regarding Boards in Cooperatives versus Corporations: Irrelevance and Incentives, in K. Karantininis and J. Nilsson (Eds.), Vertical Markets and Cooperative Hierarchies, Springer, 2007, p137-150.

Hendrikse, G.W.J. and Veerman, C.P. (2001a). Marketing Co-operatives: An Incomplete Contracting Perspective, Journal of Agricultural Economics 52(1): 53-64.

Hendrikse G.W.J. and Veerman, C.P. (2001b). Marketing Cooperatives and Financial Structure: a Transaction Costs Analysis, Agricultural Economics 26(3): 205-216.

Holmström, B. (1999). Future of Cooperatives: A Corporate Perspective, The Finnish Journal of Business Economics 4: 404-417.

Lerman, Z., and Parliament, C. (1991). Financing of Growth in Agricultural Cooperatives, No 13410, Staff Papers from University of Minnesota, Department of Applied Economics.

Merchant, K.A. (1990), The Effects of Financial Controls on Data Manipulation and Management Myopia, Accouting, Organizations and Society 15: 297-313.

Peterson, H.C. and Anderson, B.L. (1996). Cooperative Strategy: Theory and Practice, Agribusiness 12(4): 371-383.

Sexton, R.A. (1986). The Formation of Cooperatives: A Game-Theoretic Approach with Implications for Cooperative Finance, Decision Making, and Stability, American Journal of Agricultural Economics 68: 423-433.

Staatz, J.M. (1987). The Structural Characteristics of Farmer Cooperatives and their Behavioral Consequences, In J. Royer (eds). Cooperative Theory: New Approach, 33-60. USDA-ACS Service Report no. 18. Washington, D. C.

Stewart, A.L.T. (1993). Have Traditional Cooperative Structures Outlived their Usefulness? Farm Management 8(6): 287-296.

Thirkell, J.D. (1989). Attracting and Motivating Managers in U.K. Agricultural Cooperatives. In Yearbook of Cooperative Enterprise, Oxford: Plunkett Foundation.

Trechter, D.D., King, R.P., Cobia, D.W., and Hartell, J. G. (1997). Case Studies of Executive Compensation in Agricultural Cooperatives, Review of Agricultural Economics 19 (2): 492-503.

Vickers, J. (1985). Delegation and the Theory of the Firm, Economic Journal 95 (Supplement): 138-147. 
Table 1: Marginal product and performance measure parameters of different governance structures

\begin{tabular}{|c|c|c|}
\hline & IOF & Cooperative \\
\hline $\begin{array}{c}\text { Marginal product } \\
\text { downstream }\end{array}$ & $f_{D}$ & $f_{D}$ \\
\hline $\begin{array}{c}\text { Marginal product } \\
\text { upstream }\end{array}$ & 0 & $f_{U}$ \\
\hline $\begin{array}{c}\text { Performance measure } \\
\text { downstream }\end{array}$ & $g_{D}$ & 0 \\
\hline $\begin{array}{c}\text { Performance measure } \\
\text { upstream }\end{array}$ & 0 & $g_{U}$ \\
\hline
\end{tabular}

Figure 1: Performance measure choice and reaction functions

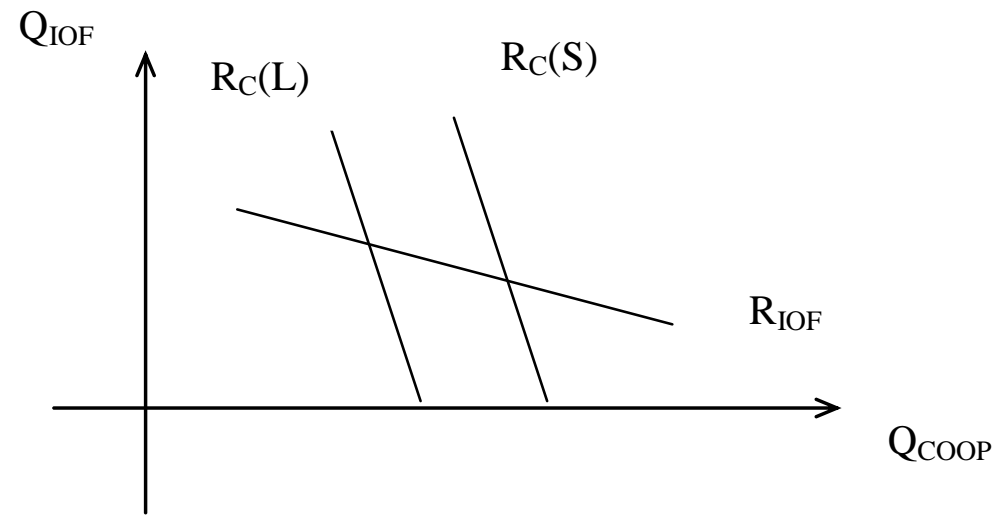




\section{Publications in the ERIM Report Series Research* in Management}

\section{ERIM Research Program: "Organizing for Performance"}

2011

Chain Interdependencies, Measurement Problems, and Efficient Governance Structure:

Cooperatives versus Publicly Listed Firms

Li Feng and George Hendrikse

ERS-2011-001-ORG

http://hdl.handle.net/1765/22720

Using a Relational Models Perspective to Understand Normatively Appropriate Conduct in Ethical Leadership

Steffen R. Giessner and Niels van Quaquebeke

ERS-2011-002-ORG

http://hdl.handle.net/1765/22721

Tango in the Dark: The Interplay of Leader's and Follower's Level of Self-Construal and its Impact on Ethical Leadership Suzanne van Gils, Niels van Quaquebeke, and Daan van Knippenberg ERS-2011-005-ORG

http://hdl.handle.net/1765/22724

* A complete overview of the ERIM Report Series Research in Management: https://ep.eur.nl/handle/1765/1

ERIM Research Programs:

LIS Business Processes, Logistics and Information Systems

ORG Organizing for Performance

MKT Marketing

F\&A Finance and Accounting

STR Strategy and Entrepreneurship 